Rev. Bras. Saúde Prod. Anim., Salvador, v.17, n.2, p.222-236 abr./jun., 2016 http://www.rbspa.ufba.br

\title{
Características quantitativas e qualitativas da carcaça e da carne de cordeiros alimentados com torta de girassol
}

\author{
Carcass and meat qualitative and quantitative characteristics of lambs receiving \\ sunflower cake
}

\begin{abstract}
BENAGLIA, Bruno Benjamin ${ }^{1 *}$; MORAIS, Maria da Graça ${ }^{2}$; OLIVEIRA, Euclides Reuter de ${ }^{3}$; COMPARIN, Marco Aurélio Scarton ${ }^{1}$; BONIN, Marina de Nadai ${ }^{4}$; FEIJÓ, Gelson Luís Dias ${ }^{4}$; RIBEIRO, Caroline Bertholini ${ }^{1}$; SOUZA, Andrea Roberto Duarte Lopes $^{2}$; ROCHA, Débora Tiburcio ${ }^{2}$; FERNANDES, Henrique Jorge ${ }^{5}$
\end{abstract}

\footnotetext{
${ }^{1}$ Universidade Federal de Mato Grosso do Sul, Faculdade de Medicina Veterinária e Zootecnia, Programa de Pós-Graduação em Ciência Animal, Campo Grande, Mato Grosso do Sul, Brasil.

${ }^{2}$ Universidade Federal de Mato Grosso do Sul, Faculdade de Medicina Veterinária e Zootecnia, Campo Grande, Mato Grosso do Sul, Brasil.

${ }^{3}$ Universidade Federal da Grande Dourados, Dourados, Mato Grosso do Sul, Brasil.

${ }^{4}$ Empresa Brasileira de Pesquisa Agropecuária, Centro Nacional de Pesquisa de Gado de Corte, Campo Grande, Mato Grosso do Sul, Brasil.

${ }^{5}$ Universidade Estadual de Mato Grosso do Sul, Aquidauana, Mato Grosso do Sul, Brasil.

*Endereço para correspondência: bruno.b.benaglia@gmail.com
}

\section{RESUMO}

Objetivou-se avaliar as características quantitativas e qualitativas da carcaça e da carne de cordeiros confinados alimentados com torta de girassol. Foram utilizados 28 cordeiros mestiços Suffolk, com quatro 4 meses de idade e peso médio de $21,00 \pm 0,74 \mathrm{~kg}$, distribuídos em quatro tratamentos: $0 \%$ (controle), $10 \%, 20 \%$ e $30 \%$ de inclusão de torta de girassol (\% MS). O critério adotado para o abate foi escore corporal (3, em escala de 1 a 5). A inclusão da torta de girassol não influenciou as medidas de comprimento e profundidade da carcaça $(\mathrm{P}>0,05), \mathrm{pH} 24$ horas $(\mathrm{P}>0,05)$, rendimentos dos cortes comerciais $(\mathrm{P}>0,05)$, assim como a distribuição de gordura, espessura de gordura subcutânea e grau de marmoreio $(\mathrm{P}>0,05)$. Houve efeito linear $(\mathrm{P}<0,035)$ e quadrático $(\mathrm{P}<0,020)$ sobre a força de cisalhamento do músculo Longissimus dorsi, indicando elevação da FC conforme aumento do nível de inclusão, não ocorrendo o mesmo para os parâmetros de cor L*, a* e b* $(\mathrm{P}>0,05)$. Em relação ao tratamento controle, a inclusão de $20 \%$ e $30 \%$ de torta de girassol influenciou negativamente a área de olho de lombo $(12,00 \mathrm{e}$ $11,43 \mathrm{~cm}^{2}$, respectivamente) $(\mathrm{P}<0,05)$, peso de carcaça fria $(13,19$ e $12,58 \mathrm{~kg}$, respectivamente) $(\mathrm{P}<0,05)$, e tempo de confinamento $(136,85 \mathrm{e}$
138,39 dias respectivamente $) \quad(\mathrm{P}<0,05) . \quad \mathrm{A}$ inclusão de até $10 \%$ de torta de girassol pode ser recomendada para uso em dietas de cordeiros em confinamento, já que permite a produção de carne e carcaças com características quantitativas e qualitativas satisfatórias, sem afetar negativamente as características de desempenho.

Palavras-chave: cor, maciez, $\mathrm{pH}$, rendimento comercial

\section{SUMMARY}

This study aimed to evaluate the quantitative and qualitative characteristics of carcass and meat of lambs fed sunflower cake. Were used 28 Suffolk crossbred lambs, with 4 months of age and average weight of $21.00 \pm 0.74 \mathrm{~kg}$, divided into four treatments: $0 \%$ (control), 10\%, $20 \%$ and $30 \%$ of sunflower cake inclusion $(\%$ $\mathrm{DM})$. The criteria adopted for the slaughter was body condition score (3, on scale of 1 to 5 ). The inclusion of sunflower cake did not influence the measurement of length and carcass depth $(\mathrm{P}>0.05), \mathrm{pH} 24$ hours $(\mathrm{P}>0.05)$, yields of commercial cuts $(\mathrm{P}>0.05)$, as well as fat distribution, fat thickness and marbling 
$(\mathrm{P}>0.05)$. There was a linear effect $(\mathrm{P}<0.035)$ and quadratic $(\mathrm{P}<0.020)$ on the shear force of the Longissimus dorsi muscle, indicating increase in SF as increase the level of inclusion, was not the case for color parameters $\mathrm{L} *, \mathrm{a} *$ and $\mathrm{b} *(\mathrm{P}>0.05)$. In relation to the control treatment, the inclusion of $20 \%$ and $30 \%$ of sunflower cake influenced negatively the ribeye area $(12.00$ and $11.43 \mathrm{~cm} 2$, respectively) $(\mathrm{P}<0.05)$, cold carcass weight $(13.19$ and 12.58 $\mathrm{kg}$, respectively) $(\mathrm{P}<0.05)$, and confinement time (136.85 and 138.39 days, respectively) $(\mathrm{P}<0.05)$. The inclusion of $10 \%$ of sunflower cake can be recommended for use in diets of feedlot lambs, since it allows the production of meat and carcasses with quantitative and qualitative characteristics satisfactory, without adversely affecting the performance characteristics.

Keywords: color, commercial cuts, $\mathrm{pH}$, tenderness

\section{INTRODUÇÃO}

A maior demanda por proteína de origem animal para alimentação humana tem sido impulsionada, essencialmente, pelo crescimento populacional aliado a melhorias no poder aquisitivo e por mudanças nos hábitos de consumo (FAO, 2012). Dentre as fontes protéicas disponíveis, a carne ovina se destaca por estar presente em todos os continentes.

A dieta afeta de forma considerável os custos de produção de carne ovina. Quando desconsiderado o gasto com a aquisição dos animais, a dieta representa em torno de $80 \%$ dos custos de produção (FORTALEZA et al., 2009). Assim, buscar alimentos alternativos para compor a dieta dos cordeiros é essencial, não só para maximizar o desempenho, mas para melhorar as características quantitativas e qualitativas da carne.

A expansão da área plantada, por ser uma oleaginosa com boa resistência à seca, ao frio e ao calor e adaptada às diferentes condições edafoclimáticas, associada à instalação de grandes empresas de extração de óleo, gera significativo volume de coprodutos com elevado potencial para utilização na alimentação animal.

Dietas contendo coprodutos, como o farelo e a torta de girassol (Helianthus annuus), possuem altas proporções de ácidos graxos poli-insaturados, altas concentrações de ácido oleico, alto teor proteico, mais de $40 \%$ de $\mathrm{PB}$, altas concentrações de vitamina $\mathrm{E}$, ferro, e de vitaminas do complexo $\mathrm{B}$ de alto valor biológico, além de alta densidade energética pelo elevado teor de óleo residual (PAULA et al., 2012).

Tendo em vista as características nutricionais e a disponibilidade dos coprodutos, estudos que avaliem o nível ideal de inclusão de torta de girassol em dietas de cordeiros são fundamentais para avaliar os possíveis efeitos sobre o desempenho, características de carcaça e da carne dos ovinos alimentados com esse ingrediente.

É necessário elucidar se fatores intrínsecos, como a alta concentração de ácidos graxos insaturados e o alto teor de extrato etéreo, considerados positivos quando se almeja elevar a qualidade da carne através de um perfil lipídico mais saudável, impactam negativamente, a depender do nível de inclusão, sobre o peso final da carcaça, por uma possível redução de consumo, por exemplo, ou mesmo sobre fatores que determinem a aparência e aspecto do produto final, como a cor, em função de pigmentos presentes nesse subproduto.

Dessa forma, objetivou-se avaliar as características quantitativas e qualitativas da carcaça e da carne de cordeiros confinados alimentados com níveis crescentes de torta de girassol. 
Rev. Bras. Saúde Prod. Anim., Salvador, v.17, n.2, p.222-236 abr./jun., 2016 http://www.rbspa.ufba.br

\section{MATERIAL E MÉTODOS}

$\mathrm{O}$ experimento foi conduzido no setor de Zootecnia da Faculdade de Ciências Agrárias / UFGD, e na Faculdade de Medicina Veterinária e Zootecnia / UFMS (sob n631/2014/CEUA). Foram confinados 28 cordeiros, mestiços Suffolk, com quatro meses de idade em média, machos não castrados, com peso médio inicial de $21,00 \pm 0,74 \mathrm{~kg}$. Os animais foram identificados com brincos numerados e vermifugados para controle de endo e ectoparasitas.

Os animais foram adaptados durante 30 dias ao manejo e às dietas e posteriormente, distribuídos através de delineamento em blocos ao acaso, com quatro tratamentos e sete repetições, em baias individuais de $1,5 \mathrm{~m}^{2} \mathrm{em}$ dois galpões cobertos, com cortinas para controle de temperatura, bebedouro e cocho móveis e piso de concreto forrado com maravalha, a qual foi reposta diariamente.

A dieta controle $(0 \%)$ foi composta de volumoso (mistura de feno de Tifton85, Tifton-68 e Jiggs (Cynodon spp), e concentrado (milho triturado, farelo de soja e minerais), formulada para atender às exigências de proteína dos animais para ganho de 200g/dia (NRC, 2007). Os animais foram distribuídos em quatro tratamentos: controle $(0 \%), 10 \%$, $20 \%$ e $30 \%$ de inclusão de torta de girassol (base da MS) (Tabela 1).

Tabela 1. Composição percentual e bromatológica dos ingredientes e das dietas experimentais

\begin{tabular}{lcccc}
\hline \multirow{2}{*}{ Ingredientes (\%MS) } & \multicolumn{4}{c}{ Inclusão de torta de girassol (\%MS) } \\
\cline { 2 - 5 } & $0 \%$ & $10 \%$ & $20 \%$ & $30 \%$ \\
\hline Feno Cynodon & 50,00 & 50 & 50 & 50 \\
Torta de Girassol & 0 & 10 & 20 & 30 \\
Milho Grão Moído & 29,65 & 22,71 & 15,77 & 8,83 \\
Farelo de Soja & 19,41 & 16,37 & 13,33 & 10,29 \\
Premix Mineral & 0,20 & 0,20 & 0,20 & 0,20 \\
Calcário & 0,73 & 0,71 & 0,69 & 0,68 \\
\hline Composição das dietas (\% MS) & & & & \\
\hline Torta de Girassol & 0 & 10 & 20 & 30 \\
Matéria Seca & 87,24 & 87,26 & 88,37 & 88,77 \\
Proteína Bruta & 17,98 & 18,15 & 17,97 & 17,66 \\
Extrato Etéreo & 1,27 & 3,43 & 5,63 & 7,18 \\
FDN & 60,22 & 61,96 & 62,54 & 60,33 \\
FDA & 30,51 & 29,83 & 29,51 & 26,80 \\
Matéria Mineral & 6,63 & 7,01 & 6,50 & 6,72 \\
\hline
\end{tabular}

Os quatro tratamentos foram balanceados para apresentarem equivalência no nível proteico, com aproximadamente $18 \%$ de PB (MS). A torta de girassol foi produzida através da prensagem mecânica, sem o uso de solventes, e o material utilizado foi processado em um único período e no mesmo equipamento (MUE-100 a frio). A proporção volumoso:concentrado usada foi de 50:50 com base na matéria seca.

O ajuste diário do consumo das dietas foi feito em função das sobras dos cochos, 
Rev. Bras. Saúde Prod. Anim., Salvador, v.17, n.2, p.222-236 abr./jun., 2016 http://www.rbspa.ufba.br ISSN 15199940

mantidas em torno de $10 \%$ para caracterizar o consumo ad libitum. O arraçoamento foi realizado duas vezes ao dia, às 8:00 e 14:00 horas e o controle higiênico do galpão experimental foi rigoroso, realizando-se diariamente a troca total de água dos bebedouros nos períodos da manhã e tarde.

Segundo as metodologias descritas pela AOAC (1990) foram determinados os teores de matéria seca (930.15), proteína bruta (968.06), matéria mineral $(942.05)$ e extrato etéreo (920.39). Para determinação das fibras em detergente neutro e em detergente ácido utilizou-se a metodologia de Van Soest (1991).

As pesagens dos animais foram realizadas a cada 14 dias, após 12 horas de jejum de sólidos. Os animais foram abatidos ao atingirem o escore de condição corporal entre 2,5 e 3,5, seguindo a escala de 1 a 5: animal $1=$ muito magro, $2=$ magro, $3=$ ligeiramente gordo, 4= gordo e 5= muito gordo, conforme proposto por Osório \& Osório (2005). Os escores foram avaliados a cada 14 dias por meio de exame visual e palpação das regiões lombar, esternal e inserção da cauda dos cordeiros. A faixa de escore utilizada corresponde à preferência do mercado consumidor para a espécie e busca evitar grandes variações na composição corporal.

Previamente ao abate os animais permaneceram em jejum de sólidos e receberam água ad libitum por um período de 16 horas. Os animais foram abatidos no abatedouro experimental da Universidade Federal da Grande Dourados (UFGD), de acordo com as normas do Regulamento da Inspeção Industrial e Sanitária de Produtos de Origem Animal - RIISPOA. Em seguida, as carcaças foram levadas para a câmara de refrigeração com ar forçado, suspensas pelas articulações tarso metatarsianas com distanciamento de 17 centímetros, onde permaneceram durante
24 horas a $4^{\circ} \mathrm{C}$. As carcaças foram seccionadas com serra fita ao longo da linha média.

As meias carcaças direita foram encaminhadas devidamente refrigeradas à Embrapa Gado de Corte, em Campo Grande - MS, pesadas e em seguida obtido o valor de $\mathrm{pH}$ (24 horas após o abate) por meio de peagâmetro portátil (Hanna Modelo HI99163) com eletrodo de inserção, nos músculos Semimembranosus, Tríceps brachii e Longissimus dorsi (L. dorsi).

$\mathrm{Na}$ sequencia foram obtidos $\mathrm{o}$ comprimento interno da carcaça (distância entre os pontos médios da borda cranial do púbis e a borda cranial da primeira costela), comprimento da perna (distância entre o bordo anterior da sínfise ísquio - pubiana e a porção média dos ossos do tarso), comprimento externo da carcaça (distância entre a base da cauda e a base do pescoço), distribuição de gordura (1 - carcaça sem acabamento, 2- carcaça com falhas no acabamento e 3 - carcaça com distribuição uniforme) e profundidade do tórax (distância entre o esterno e o dorso da carcaça).

O músculo Longissimus dorsi foiexposto, através de corte transversal realizado entre a $12^{\mathrm{a}}$ e a $13^{\mathrm{a}}$ vértebras torácicas, para determinação dos valores de textura (1 - muito grosseira, 2 grosseira, 3 - média, 4 - fina e 5 - muito fina), grau de marmorização (1-3 traços, 4-6 leve, 7-9 pequeno, 10-12 médio, 1315 moderado e 16-18 abundante), sendo traçado seu perímetro em papel vegetal e digitalizado para determinação da área de olho de lombo (AOL) pelo software DDA v.1.2 (Instituto Federal Farroupilha, Santo Augusto, RS, Brasil). Nesta mesma secção transversal, com auxílio de paquímetro digital, foi medido no terço final do músculo, a espessura de gordura subcutânea (EGS) e avaliada a cor em duplicata no músculo, utilizando- 
se o colorímetro Mini SCan XE PLUS, modelo 45/0-L. O sistema de avaliação utilizado foi o CIELab.

Posteriormente, as meias carcaças foram divididas em cortes comerciais e pesadas separadamente para cálculo dos seus rendimentos em relação ao peso da meia carcaça. Em seguida, cada corte foi separado em tecidos muscular, adiposo e ósseo para determinação da composição tecidual.

Foram retiradas amostras de $2,5 \mathrm{~cm}$ da parte medial dos músculos Triceps brachii, Longissimus dorsi e Semimembranosus, que aparadas da gordura de cobertura, foram embaladas e congeladas a $18^{\circ} \mathrm{C}$ para posteriores análises do $\mathrm{pH}$, cor $\left(\mathrm{L}^{*}, \mathrm{a}^{*}\right.$ e $\left.\mathrm{b}^{*}\right)$ e força de cisalhamento (FC).As amostras dos músculos L. dorsi, Triceps brachii e Semimembranosus foram descongeladas por 24 horas em refrigerador a $4^{\circ} \mathrm{C}$ e após a exposição da superfície das amostras ao ambiente por cerca de 30 minutos, foram realizadas as avaliações da cor através de colorímetro Mini SCan XE PLUS, modelo 45/0-L. As amostras foram pesadas e submetidas ao cozimento em forno elétrico préaquecido, a uma temperatura de $170^{\circ} \mathrm{C}$, até alcançarem a temperatura de $71^{\circ} \mathrm{C}$ no centro geométrico. Em seguida, foram retiradas do forno e permaneceram em temperatura ambiente até atingirem $28^{\circ} \mathrm{C}$, momento em que foram pesadas novamente para determinação das perdas por cocção. De cada amostra assada, foram retiradas subamostras cilíndricas para determinação da força de cisalhamento (kgf), utilizando-se o aparelho TextureAnalyser TA XT plus, acoplado à lâmina Warner-Bratzler.

$\mathrm{O}$ delineamento experimental foi inteiramente casualizado, com sete repetições por tratamento. Foram avaliados os efeitos dos níveis de inclusão de torta de girassol sobre as variáveis quantitativas e qualitativas da carne e da carcaça. Quando identificado efeito significativo dos níveis de inclusão da torta de girassol, comparou-se o tratamento controle com os demais, utilizando-se o teste de Dunnett e estudados os efeitos lineares e quadráticos. Utilizou-se o peso corporal ao abate como covariável em todas as análises. Utilizou-se o PROC GLM do SAS Versão 9.3 e adotou-se o nível de significância de 5\% em todas as análises.

\section{RESULTADOS E DISCUSSÃO}

Os animais alimentados com 20 e $30 \%$ de torta de girassol na dieta permaneceram mais tempo confinados e apresentaram menores pesos de carcaça fria $(\mathrm{P}>0,05)$ (Tabela 2).

Embora o desempenho produtivo não tenha sido objeto deste trabalho, é preciso citá-lo, já que afeta diretamente os padrões das carcaças. Verificou-se que maiores níveis de inclusão de torta foram responsáveis por menores ganhos de peso, onde o tratamento controle e os níveis de inclusão de 10,20 e $30 \%$ proporcionaram ganhos diários de $184 \mathrm{~g}$, $150 \mathrm{~g}, 112 \mathrm{~g}$ e $74 \mathrm{~g}$, respectivamente. Os tratamentos com inclusão de 20 e $30 \%$ de torta (base na MS) tiveram desempenho inferior ao controle $(\mathrm{P}<0,05)$.

Fernandes Júnior et al. (2013), quando avaliaram níveis crescentes de inclusão de torta de girassol na dieta de ovinos confinados $(0,11,22,33$ e $44 \%$ da matéria seca), após 60 dias de confinamento obtiveram carcaças com pesos de $16,95 \mathrm{~kg}, 14,87 \mathrm{~kg}, 13,97 \mathrm{~kg}$, $13,48 \mathrm{~kg}$ e $11,93 \mathrm{~kg}$ respectivamente, estes valores são próximos aos encontrados neste trabalho.

O aumento do período de confinamento e redução dos pesos de carcaça com a inclusão de níveis mais elevados de 
Rev. Bras. Saúde Prod. Anim., Salvador, v.17, n.2, p.222-236 abr./jun., 2016 http://www.rbspa.ufba.br ISSN 15199940

inclusão de torta de girassol são consequências do desempenho inferior dos animais. O menor desempenho ocorreu devido a um provável menor consumo de matéria seca observado com os níveis crescentes de inclusão de torta de girassol, que aumentou os teores de extrato etéreo das dietas (Tabela 1).

$\mathrm{O}$ excesso de extrato etéreo possui efeito deletério sobre a utilização das dietas pelo organismo do animal. Segundo Palmquist \& Mattos (2006), dietas com mais de $5 \%$ de EE comprometem, como apresentada pelos níveis de 20 e $30 \%$ de inclusão de torta de girassol (Tabela 1), o consumo devido aos mecanismos regulatórios que atuam sobre a ingestão e degradação dos lipídios no ambiente ruminal.

Tabela 2. Peso da carcaça fria (PCF) e dias de confinamento de cordeiros mestiços de cruzamento Suffolk recebendo diferentes níveis de torta de girassol

\begin{tabular}{lccccccc}
\hline \multirow{2}{*}{ Variável } & \multirow{2}{*}{ Controle } & \multicolumn{2}{c}{ Nível de inclusão de torta $(\% \mathrm{MS})$} & \multirow{2}{*}{ CV $(\%)$} & \multicolumn{2}{c}{ P-Valor } \\
\cline { 3 - 4 } \cline { 3 - 4 } & & $10 \%$ & $20 \%$ & $30 \%$ & & Linear & Quadrático \\
\hline PCF $(\mathrm{kg})$ & 14,97 & 14,56 & $13,19^{*}$ & $12,58^{*}$ & 6,36 & 0,242 & 0,492 \\
Dias & 88,61 & 86,84 & $136,85^{*}$ & $138,39^{*}$ & 23,34 & 0,063 & 0,130 \\
\hline
\end{tabular}

Médias seguidas de (*) diferem do tratamento controle pelo teste de Dunnett em nível de 5\%.

$\mathrm{CV}=$ coeficiente de variação.

$\mathrm{O}$ alto teor de lipídeos na dieta, principalmente ácidos graxos insaturados presentes na torta de girassol (TELLES, 2006), causam efeitos tóxicos aos microrganismos e afetam a permeabilidade da membrana celular, principalmente sobre as bactérias Gram + e protozoários, responsáveis pela digestão da fibra da dieta. Com a redução da degradação da fibra, ocorre diminuição da taxa de passagem de partículas para outros compartimentos do trato gastrintestinal, comprometendo o consumo e ganho de peso, já que nesta situação as exigências nutricionais não são atendidas devido à menor disponibilidade de matéria seca.

Apesar de ser observada uma redução significativa nos pesos de carcaça fria nos animais alimentados com 20 e $30 \%$ de inclusão de torta de girassol, as medidas da carcaça (Tabela 3) e o rendimento dos cortes comerciais (Tabela 4) não foram afetados ( $\mathrm{P}>0,05)$.

Tabela 3. Medidas da carcaça de cordeiros mestiços de cruzamento Suffolk confinados recebendo diferentes níveis de torta de girassol

\begin{tabular}{lccccccc}
\hline \multirow{2}{*}{ Variável } & \multirow{2}{*}{ Controle } & \multicolumn{2}{c}{ Nível de inclusão de torta $(\% \mathrm{MS})$} & \multirow{2}{*}{ CV (\%) } & \multicolumn{2}{c}{ P-Valor } \\
\cline { 3 - 5 } & & $10 \%$ & $20 \%$ & $30 \%$ & & Linear & Quadrático \\
\hline CIC & 63,06 & 61,52 & 60,12 & 61,35 & 4,92 & 0,320 & 0,332 \\
CP & 29,47 & 29,45 & 28,91 & 29,36 & 5,02 & 0,517 & 0,528 \\
PT & 26,22 & 26,16 & 25,78 & 25,62 & 4,12 & 0,746 & 0,827 \\
CEC & 72,30 & 71,53 & 72,31 & 71,80 & 2,63 & 0,480 & 0,498 \\
\hline
\end{tabular}

Médias seguidas de (*) diferem do tratamento controle pelo teste de Dunnett em nível de 5\%.

Comprimento interno da carcaça (CIC), comprimento do pernil (CP), profundidade do tórax (PT) e comprimento externo da carcaça (CEC).

$\mathrm{CV}=$ coeficiente de variação. 
Rev. Bras. Saúde Prod. Anim., Salvador, v.17, n.2, p.222-236 abr./jun., 2016 http://www.rbspa.ufba.br

Como o crescimento tecidual ocorre de forma proporcional por toda a carcaça, e as comparações são entre animais contemporâneos e em curtos intervalos de tempo, provavelmente as dietas oferecidas não foram capazes de interferir sobre tais características (Tabela 4).

Fernandes Júnior et al. (2013) quando incluíram torta de girassol em níveis próximos a $11,22,33$ e $44 \%$ da matéria seca na dieta de cordeiros Suffolk, também não encontraram efeitos das dietas sobre medidas biométricas e características de carcaça. Ao testarem subprodutos de oleaginosas (inclusive a torta de girassol) como fontes alternativas na alimentação de cordeiros em terminação, Santos et al. (2011) observaram que os rendimentos dos cortes da carcaça não foram influenciados pelas dietas.

Tabela 4. Rendimento dos cortes comerciais de cordeiros mestiços de cruzamento Suffolk confinados recebendo diferentes níveis de torta de girassol

\begin{tabular}{lccccccc}
\hline \multirow{2}{*}{ Variável } & \multirow{2}{*}{ Controle } & \multicolumn{3}{c}{ Nível de inclusão de torta $(\% \mathrm{MS})$} & \multirow{2}{*}{$\mathrm{N}(\%)$} & \multicolumn{2}{c}{ P-Valor } \\
\cline { 3 - 5 } \cline { 7 - 8 } & & $10 \%$ & $20 \%$ & $30 \%$ & & Linear & Quadrático \\
\hline Pernil & 32,49 & 32,30 & 32,82 & 33,35 & 4,90 & 0,983 & 0,883 \\
Paleta & 18,51 & 18,99 & 18,92 & 19,71 & 6,45 & 0,561 & 0,483 \\
Lombo & 9,67 & 9,28 & 8,98 & 8,95 & 12,14 & 0,872 & 0,935 \\
Pescoço & 6,36 & 5,87 & 8,20 & 6,02 & 24,47 & 0,016 & 0,017 \\
Costela/fralda & 19,76 & 19,36 & 18,17 & 18,25 & 8,09 & 0,337 & 0,421 \\
Carré & 13,92 & 14,19 & 12,90 & 13,72 & 12,34 & 0,305 & 0,342 \\
\hline
\end{tabular}

Médias seguidas de (*) diferem do tratamento controle pelo teste de Dunnett em nível de 5\%.

$\mathrm{CV}=$ coeficiente de variação.

Os rendimentos dos cortes comerciais encontrados neste trabalho estão de acordo aos valores obtidos por Reis et al. (2001) ao estudarem as características de carcaça de ovinos confinados recebendo grãos de milho conservados de diferentes formas. Estes autores observaram rendimentos de pernil variando entre 31,80 a $35,29 \%$, paleta de 17,31 a $23,50 \%$, lombo de 8,45 a $9,62 \%$ e pescoço de 4,86 a $7,36 \%$.

Os níveis de inclusão de torta de girassol não alteraram as proporções de ossos, músculo e gordura dos cortes comerciais avaliados, exceto do pescoço e pernil (Tabela 5). A inclusão de 10\% do coproduto reduziu significativamente a proporção de músculos no pernil e pescoço $(\mathrm{P}<0,05)$. Estes resultados podem estar associados à precocidade dos animais para deposição de tecido muscular nos respectivos cortes, acelerada pelas rápidas taxas de crescimento proporcionadas pela dieta com $10 \%$ de inclusão de torta de girassol, indicadas pelo ganho médio diário.

$\mathrm{O}$ pescoço e membros correspondem às regiões de desenvolvimento mais precoce no animal, logo se espera que as suas proporções de músculos diminuam com o crescimento dos respectivos cortes (pescoço e pernil) à medida que atingem o tamanho adulto. Além disso, a precocidade de desenvolvimento contribui para aumento deposição da gordura. Isto significa que o desempenho satisfatório, que se deu em função da dieta, contribuiu para que estes animais atingissem desenvolvimento ósseo e muscular completo, quando passaram a depositar maior proporção de gordura, reduzindo a quantidade de músculo em relação ao peso total dos cortes. 
Rev. Bras. Saúde Prod. Anim., Salvador, v.17, n.2, p.222-236 abr./jun., 2016 http://www.rbspa.ufba.br ISSN 15199940 http://dx.doi.org/10.1590/S1519-99402016000200010

Tabela 5. Componentes físicos de diferentes cortes cárneos de cordeiros mestiços de cruzamento Suffolk confinados recebendo diferentes níveis de torta de girassol

\begin{tabular}{|c|c|c|c|c|c|c|c|c|}
\hline \multirow{2}{*}{ Cortes } & \multirow{2}{*}{$\begin{array}{c}\text { Variável } \\
(\%)\end{array}$} & \multirow[t]{2}{*}{ Controle } & \multicolumn{3}{|c|}{$\begin{array}{l}\text { Nível de inclusão de torta } \\
\text { (\% MS) }\end{array}$} & \multirow{2}{*}{$\begin{array}{l}\text { CV } \\
(\%)\end{array}$} & \multicolumn{2}{|c|}{ P-Valor } \\
\hline & & & $10 \%$ & $20 \%$ & $30 \%$ & & Linear & Quadrático \\
\hline \multirow{3}{*}{ Pernil } & Ossos & 18,93 & 21,03 & 19,27 & 20,55 & 7,64 & 0,110 & 0,130 \\
\hline & Músculos & 68,80 & $64,08^{*}$ & 66,44 & 66,79 & 3,43 & 0,132 & 0,227 \\
\hline & Gorduras & 12,26 & 14,89 & 14,28 & 12,66 & 20,08 & 0,927 & 0,940 \\
\hline \multirow{3}{*}{ Paleta } & Ossos & 22,60 & 21,65 & 23,32 & 23,43 & 7,32 & 0,205 & 0,299 \\
\hline & Músculos & 61,01 & 58,86 & 59,62 & 61,35 & 5,75 & 0,925 & 0,955 \\
\hline & Gorduras & 16,38 & 19,48 & 17,05 & 15,23 & 22,82 & 0,545 & 0,704 \\
\hline \multirow{3}{*}{ Lombo } & Ossos & 21,04 & 24,13 & 19,95 & 24,27 & 22,96 & 0,172 & 0,173 \\
\hline & Músculos & 63,80 & 59,49 & 62,31 & 63,54 & 7,39 & 0,604 & 0,753 \\
\hline & Gorduras & 15,15 & 16,37 & 17,74 & 12,18 & 23,69 & 0,195 & 0,133 \\
\hline \multirow{3}{*}{ Pescoço } & Ossos & 30,53 & 32,00 & 26,02 & 24,81 & 28,68 & 0,467 & 0,581 \\
\hline & Músculos & 52,27 & $44,12 *$ & 49,06 & 53,11 & 8,36 & 0,534 & 0,867 \\
\hline & Gorduras & 17,19 & 23,88 & 24,91 & 22,08 & 32,70 & 0,632 & 0,593 \\
\hline \multirow{3}{*}{ Costela } & Ossos & 14,40 & 14,13 & 14,49 & 16,03 & 16,11 & 0,727 & 0,595 \\
\hline & Músculos & 45,83 & 43,34 & 50,93 & 51,94 & 10,13 & 0,111 & 0,208 \\
\hline & Gorduras & 39,77 & 42,52 & 34,57 & 32,02 & 14,58 & 0,185 & 0,346 \\
\hline \multirow{3}{*}{ Carré } & Ossos & 24,92 & 26,58 & 24,84 & 26,89 & 14,89 & 0,425 & 0,419 \\
\hline & Músculos & 53,08 & 48,43 & 51,93 & 52,00 & 8,04 & 0,333 & 0,427 \\
\hline & Gorduras & 21,11 & 24,98 & 23,22 & 21,11 & 20,38 & 0,816 & 0,968 \\
\hline
\end{tabular}

Médias seguidas de $(*)$ diferem do tratamento controle pelo teste de Dunnett em nível de 5\%.

$\mathrm{CV}=$ coeficiente de variação.

Os valores médios de $\mathrm{pH} 24$ horas não diferiram entre o tratamento controle e os níveis de inclusão de torta estudados (Tabela 6). Segundo Silva Sobrinho et al. (2005), o valor do $\mathrm{pH}$ final na carne ovina geralmente varia entre 5,5 a 5,8 , valores que indicam adequado manejo e abate dos animais (SILVA SOBRINHO et al., 2005).

Ao avaliarem dois níveis de concentrado e três grupos genéticos de cordeiros, Costa et al. (2011) não observaram diferenças nos valores de $\mathrm{pH}$ das carnes, assim como Gonçalves et al. (2004), que encontraram valores de $\mathrm{pH}$ variando entre 5,40 e 5,77, ao avaliarem carcaças de ovinos sem raça definida (SRD).

As variações de $\mathrm{pH}$ estão mais relacionadas a fatores como estresse pré-abate e procedimentos inadequados de abate (RAMOS \& GOMIDE, 2009), mas é importante salientar, que nenhuma das dietas estudadas apresentou efeitos deletérios sobre os valores de $\mathrm{pH}$, que se apresentaram dentro da faixa considerada essencial para o estabelecimento adequado do rigor mortis e transformação do músculo em carne.

As características distribuição de gordura, espessura de gordura subcutânea e marmorização não foram afetadas pelos diferentes níveis de inclusão de torta de girassol $(\mathrm{P}>0,05)$. Os níveis de inclusão utilizados não foram suficientes para que ocorresse uma elevação considerável na quantidade de ácidos graxos absorvidos e não favoreceu um aumento significativo na deposição de tecidos adiposos de cobertura e intramuscular. 
Rev. Bras. Saúde Prod. Anim., Salvador, v.17, n.2, p.222-236 abr./jun., 2016 http://www.rbspa.ufba.br ISSN 15199940

Tabela 6. Valores de $\mathrm{pH}$ às $24 \mathrm{~h}$, textura, distribuição de gordura (DG), espessura de gordura subcutânea (EGS), marmoreio e área de olho de lombo (AOL) de cordeiros mestiços de cruzamento Suffolk confinados recebendo diferentes níveis de torta de girassol

\begin{tabular}{lccccccc}
\hline \multirow{2}{*}{ Variável } & \multirow{2}{*}{ Controle } & \multicolumn{3}{c}{ Nível de inclusão de torta (\% MS) } & \multirow{2}{*}{ CV $(\%)$} & \multicolumn{3}{c}{ P-Valor } \\
\cline { 3 - 5 } \cline { 6 - 7 } & & $10 \%$ & $20 \%$ & $30 \%$ & & Linear & Quadrático \\
\hline pH & 5,80 & 5,75 & 5,67 & 5,91 & 5,43 & 0,418 & 0,355 \\
Textura (1-5) & 4,05 & 4,00 & 4,21 & 4,09 & 12,60 & 0,444 & 0,460 \\
D G (1-3) & 2,02 & 1,79 & 1,98 & 1,60 & 22,96 & 0,301 & 0,263 \\
EGS (mm) & 1,22 & 0,91 & 0,54 & 0,64 & 63,15 & 0,196 & 0,238 \\
Marmoreio (1-18) & 3,06 & 1,98 & 2,82 & 2,13 & 38,03 & 0,157 & 0,168 \\
AOL $\left(\mathrm{cm}^{2}\right)$ & 15,38 & 13,09 & $12,00^{*}$ & $11,43^{*}$ & 18,19 & 0,704 & 0,812 \\
\hline
\end{tabular}

Médias seguidas de (*) diferem do tratamento controle pelo teste de Dunnett em nível de 5\%.

Textura 1 - muito grosseira, 2 - grosseira, 3 - média, 4 - fina e 5 - muito fina.

D G 1 - Carcaça sem acabamento, 2- Carcaça com falhas no acabamento e 3= Carcaça com distribuição uniforme.

Marmoreio 1-3 traços, 4-6 leve, 7-9 pequeno, 10-12 médio, 13-15 moderado e 16-18 abundante.

$\mathrm{CV}=$ coeficiente de variação.

Em função dos efeitos negativos, nos níveis de inclusão de 20 e $30 \%$ de torta, sobre o desempenho, devidos à provável redução no consumo de matéria seca, os animais desses dois tratamentos não demonstraram todo o potencial para aproveitamento da dieta, e para assim aumentarem a deposição de gordura nas carcaças.

É preciso considerar que a intensidade de deposição de tecido adiposo é influenciada, além da dieta, por características genéticas e pela fase de desenvolvimento fisiológico, sendo este o último tecido a ser depositado considerando o perfil da curva de crescimento do animal.

A inclusão de 20 e $30 \%$ de torta de girassol na dieta implicou em redução da AOL $(\mathrm{P}<0,05)$. A redução da $\mathrm{AOL}$ ocorreu como reflexo do desempenho inferior e menor peso da carcaça fria apresentados pelos animais destes tratamentos quando comparados ao tratamento controle. Esta variável, quando medida entre a $12^{\mathrm{a}}$ e $13^{\mathrm{a}}$ costelas, é considerada medida representativa da quantidade e distribuição das massas musculares (HASHIMOTO et al., 2007). $\mathrm{O}$ menor peso ao abate resulta em carcaças mais leves e com L. dorsi menor, pois este não se desenvolve completamente. Segundo Sainz (1996), os músculos de maturidade tardia são mais apropriados para representar $\mathrm{o}$ desenvolvimento e volume do tecido muscular, por isso o Longissimus dorsi é o mais indicado, além de ser de fácil mensuração. Porém, no presente trabalho os animais dos tratamentos com 20 e $30 \%$ de inclusão de torta de girassol não atingiram o tamanho a maturidade devido aos desempenhos inferiores, fato que contribuiu para redução da deposição de tecido muscular e consequentemente da AOL do L. dorsi.

Os valores de AOL dos animais dos tratamentos controle e com $10 \%$ de inclusão de torta de girassol foram próximos aos obtidos por Fernandes Júnior et al. (2013) e Moreno et al. (2010) quando avaliaram carcaças de cordeiros confinados Ile de France com 180 dias de idade $\left(12,94\right.$ e $13,25 \mathrm{~cm}^{2}$, respectivamente), mostrando que esse nível de inclusão favoreceu um adequado desenvolvimento muscular dos animais.

Os diferentes níveis de inclusão de torta de girassol não alteraram os valores 
Rev. Bras. Saúde Prod. Anim., Salvador, v.17, n.2, p.222-236 abr./jun., 2016 http://www.rbspa.ufba.br ISSN 15199940

médios para luminosidade $\left(\mathrm{L}^{*}\right)$, teor de vermelho $\left(a^{*}\right)$ e do teor de amarelo $\left(b^{*}\right)$ encontrados no pernil, paleta e lombo (Tabela 7). Esse resultado permite inferir que a inclusão desse coproduto não acarreta em efeitos deletérios sobre a cor da carne, parâmetro relacionado à qualidade do produto final, de extrema importância no momento da compra pelo consumidor.

Tabela 7. Médias dos parâmetros de cor onde $\mathrm{L}^{*}$ corresponde à luminosidade; $\mathrm{a}^{*}$ à tonalidade de vermelho e $b^{*}$ à de amarelo do Pernil (Semimembranosus), Paleta (Triceps brachii) e Lombo (Longissimus dorsi) de cordeiros mestiços de cruzamento Suffolk confinados recebendo diferentes níveis de torta de girassol

\begin{tabular}{|c|c|c|c|c|c|c|c|c|}
\hline \multirow{2}{*}{ Cortes } & \multirow{2}{*}{ Variável } & \multirow{2}{*}{ Controle } & \multicolumn{3}{|c|}{ Nível de inclusão de torta (\% MS) } & \multirow{2}{*}{ CV $(\%)$} & \multicolumn{2}{|c|}{ P-Valor } \\
\hline & & & $10 \%$ & $20 \%$ & $30 \%$ & & Linear & Quadrático \\
\hline \multirow{3}{*}{ Pernil } & $\mathrm{L}^{*}$ & 40,77 & 41,44 & 40,77 & 41,30 & 5,94 & 0,443 & 0,444 \\
\hline & $a^{*}$ & 13,93 & 13,26 & 13,21 & 14,18 & 12,77 & 0,775 & 0,687 \\
\hline & $b^{*}$ & 14,55 & 14,42 & 14,26 & 14,32 & 8,88 & 0,814 & 0,824 \\
\hline \multirow{3}{*}{ Paleta } & $\mathrm{L}^{*}$ & 41,48 & 39,55 & 42,42 & 40,37 & 6,14 & 0,092 & 0,106 \\
\hline & $a^{*}$ & 13,44 & 14,72 & 13,51 & 14,32 & 9,98 & 0,125 & 0,138 \\
\hline & $b^{*}$ & 14,22 & 15,57 & 14,69 & 15,68 & 6,91 & 0,100 & 0,098 \\
\hline \multirow{3}{*}{ Lombo } & $\mathrm{L}^{*}$ & 41,59 & 40,78 & 41,15 & 41,05 & 5,76 & 0,828 & 0,849 \\
\hline & $a^{*}$ & 13,90 & 13,73 & 14,01 & 13,02 & 11,04 & 0,661 & 0,602 \\
\hline & $b^{*}$ & 16,17 & 15,54 & 15,75 & 15,68 & 6,11 & 0,870 & 0,903 \\
\hline
\end{tabular}

Médias seguidas de $(*)$ diferem do tratamento controle pelo teste de Dunnett em nível de $5 \%$.

$\mathrm{CV}=$ coeficiente de variação.

Resultado similar foi encontrado por Fernandes Júnior et al. (2013), quando avaliaram os efeitos da inclusão de torta de girassol na dieta de ovinos confinados e não observaram efeitos da dieta sobre os parâmetros de cor, com valores médios de 36,91 para $L^{*}, 14,60$ para $\mathrm{a}^{*}$ e 10,34 para $\mathrm{b}^{*}$ no músculo $L$. dorsi.

Os níveis de inclusão de torta não diferiram do tratamento controle quanto às perdas por descongelamento (PPD) e perdas por cocção (PPC) do pernil, paleta e lombo (Tabela 8).

Os resultados encontrados são reflexos do pH obtido após o abate (Tabela 6), considerado dentro da faixa ideal para não modificar as características físicas e químicas da carne. As perdas de líquidos, seja pelo descongelamento ou cocção, são dependentes da capacidade de retenção de água (CRA), que é a capacidade da carne em reter água durante aplicação de forças externas, tais como o corte, aquecimento, trituração, prensagem e a gravidade (RAMOS \& GOMIDE, 2009).

Haja vista a importância da CRA, e sua associação com as perdas de líquidos por cocção e descongelamento, pode-se afirmar, através dos resultados obtidos, que a utilização da torta de girassol nos níveis estudados não afetou de forma negativa os parâmetros acima citados, o que é indispensável quando se considera a qualidade da carne produzida. 
Rev. Bras. Saúde Prod. Anim., Salvador, v.17, n.2, p.222-236 abr./jun., 2016 http://www.rbspa.ufba.br ISSN 15199940

Tabela 8. Perdas por descongelamento (PPD), perdas por cocção (PPC) e força de cisalhamento (FC) do Semimembranosus (pernil), Triceps brachii (paleta) e L. dorsi (lombo) de cordeiros mestiços de cruzamento Suffolk confinados recebendo diferentes níveis de torta de girassol

\begin{tabular}{|c|c|c|c|c|c|c|c|c|}
\hline \multirow{2}{*}{ Músculo } & \multirow{2}{*}{ Variável } & \multirow[t]{2}{*}{ Controle } & \multicolumn{3}{|c|}{$\begin{array}{l}\text { Nível de inclusão de torta } \\
\text { (\% MS) }\end{array}$} & \multirow[t]{2}{*}{ CV (\%) } & \multicolumn{2}{|c|}{ P-Valor } \\
\hline & & & $10 \%$ & $20 \%$ & $30 \%$ & & Linear & Quadrático \\
\hline \multirow{3}{*}{ Pernil } & PPD (\%) & 10,52 & 9,67 & 12,85 & 12,29 & 19,96 & 0,171 & 0,273 \\
\hline & PPC (\%) & 28,73 & 30,54 & 30,22 & 31,68 & 10,05 & 0,618 & 0,561 \\
\hline & $\mathrm{FC}\left(\mathrm{kgf} / \mathrm{cm}^{2}\right)$ & 3,05 & 2,49 & 3,16 & 3,18 & 19,51 & 0,213 & 0,313 \\
\hline \multirow{3}{*}{ Paleta } & PPD (\%) & 9,28 & 8,64 & 8,75 & 8,44 & 21,74 & 0,781 & 0,758 \\
\hline & PPC (\%) & 29,05 & 23,46 & 22,54 & 23,83 & 24,60 & 0,939 & 0,942 \\
\hline & $\mathrm{FC}\left(\mathrm{kgf} / \mathrm{cm}^{2}\right)$ & 2,44 & 1,88 & 2,20 & 2,70 & 27,75 & 0,885 & 0,896 \\
\hline \multirow{3}{*}{ Lombo } & PPD (\%) & 10,86 & 8,60 & 10,01 & 9,47 & 23,08 & 0,542 & 0,609 \\
\hline & PPC (\%) & 21,04 & 26,07 & 20,85 & 25,79 & 17,12 & 0,038 & 0,039 \\
\hline & $\mathrm{FC}\left(\mathrm{kgf} / \mathrm{cm}^{2}\right)$ & 2,51 & 2,69 & 2,34 & 3,68 & 15,79 & 0,035 & 0,020 \\
\hline
\end{tabular}

Médias seguidas de $\left(^{*}\right)$ diferem do tratamento controle pelo teste de Dunnett em nível de $5 \%$.

$\mathrm{CV}=$ coeficiente de variação.

As perdas de água ocorrem pelas superfícies musculares expostas das carcaças ou dos cortes e, dependendo da quantidade exsudada, pode influenciar a cor, a textura e a maciez da carne crua, além do sabor e odor da carne cozida (SILVA et al., 2008). Segundo Zeola et al. (2007), a menor CRA da carne é responsável por maiores perdas por cocção e do valor nutritivo, uma vez que, junto com a água, são perdidas proteínas solúveis, lipídios, vitaminas e minerais.

Os valores de PPD e PPC obtidos estão de acordo com os obtidos por Bressan et al. (2001) quando avaliaram características físico-químicas da carne de cordeiros de diferentes raças e pesos ao abate com perdas de 27,2 a $29,1 \%$ no $L$. dorsi e de 29,4 a $33,1 \%$ no Semimembranosus, considerados dentro da normalidade.

Os valores médios de força de cisalhamento (FC) não foram afetados pelos níveis de inclusão de torta de girassol na dieta dos cordeiros $(\mathrm{P}>0,05$; Tabela 8). As médias de FC dos cortes avaliados oscilaram entre 1,88 e $3,68 \mathrm{kgf}$, consideradas macias, conforme Boleman et al. (1997). Os autores classificaram a maciez da carne segundo a FC em: macia (2,3 a 3,6kgf), intermediária $(4,1$ a $5,4 \mathrm{kgf})$ e dura $(5,9$ a 7,2kgf). Bressan et al. (2001) trabalharam com diferentes raças e pesos ao abate e observaram valores similares para FC dos músculos Semimembranosus e L. dorsi, com 2,3 a 2,8 e 2,5 a 3,2kgf, respectivamente.

Nota-se que os níveis de utilização de torta de girassol não prejudicaram a maciez da carne, já que os valores obtidos estão dentro do padrão para esta espécie. No entanto, observou-se um efeito linear e quadrático positivo dos níveis crescentes de inclusão de torta de girassol sobre a força de cisalhamento do lombo $(\mathrm{P}<0,05)$, ou seja, houve redução da maciez do lombo com aumento do teor de torta de girassol na dieta.

Tal fato pode estar associado à idade ao abate dos animais, pois estes permaneceram mais tempo no 
Rev. Bras. Saúde Prod. Anim., Salvador, v.17, n.2, p.222-236 abr./jun., 2016 http://www.rbspa.ufba.br ISSN 15199940

confinamento (Tabela 2), devido ao menor ganho de peso, até atingirem o escore de abate preconizado. Segundo Hadlich et al. (2006), o aumento da idade diminui a solubilidade de proteínas estromáticas (colágeno $\mathrm{e}$ elastina), diminuindo a maciez do corte. Além disso, o menor ganho de peso resulta em diminuição da hipertrofia muscular, reduzindo a densidade das fibras musculares e seu desenvolvimento, aumentando a FC do corte (ORTIZ et al, 2005).

Animais abatidos com maior peso e menor idade apresentam maior desenvolvimento muscular e o $L$. dorsi com menores valores de força de cisalhamento (ORTIZ et al., 2005; DANTAS et al., 2008). Os dados de AOL obtidos reforçam essa teoria, já que os animais alimentados com 20 e $30 \%$ de torta de girassol na dieta apresentaram menores valores de AOL quando comparados ao tratamento controle (Tabela 5).

Os animais dos tratamentos com 20 e $30 \%$ de inclusão apresentaram menor peso de carcaça fria, provavelmente devido a um menor consumo de MS, e assim ingeriram menor quantidade de $\mathrm{PB}$, o que prejudicou o ganho de peso, o desenvolvimento muscular e consequentemente a maciez da carne. É importante salientar que o lombo é um músculo de desenvolvimento tardio (SAINZ, 1996) e provavelmente esta tenha sido a causa de somente este músculo ter sofrido os efeitos acima descritos.

A inclusão de até $10 \%$ de torta de girassol é recomendada para uso em dietas de cordeiros em confinamento, pois garante a produção de carcaças e de carne com características quantitativas e qualitativas satisfatórias.

\section{REFERÊNCIAS}

ASSOCIATION OF OFFICIAL ANALYTICAL CHEMISTRY AOAC. Official methods of analysis of AOAC international. $15^{\text {th }}$ ed.

Arlington, 1990.

BOLEMAN, S.J.; BOLEMAN, S.L.; MILLER, R.K.; TAYLOR, J.F.; CROSS, H.R.; WHEELER, T.L.; KOOHMARAIE, M.; SHACKELFORD, S.D.; MILLER, M.F.; JOHNSON, D.D.; SAVELL, J.W. Consumer evaluation of beef of know categories of tenderness. Journal of Animal Science, v.75, n.6, p.15211524, 1997.

BRESSAN, M.C.; PRADO, O.V.; PÉREZ, J.R.O.; LEMOS, A.L.S.C.; BONAGURIO, S. Efeito do peso ao abate de cordeiros Santa Inês e Bergamácia sobre as características físico-químicas da carne. Ciência e Tecnologia de Alimentos, v.21, n.3, p.293-303, 2001.

CASTRO, C.; CASTIGLIONI, V.B.R.; BALLA, A. A cultura do girassol: tecnologia de produção. Londrina: EMBRAPA-CNPSo, 1996. 38p.

(Documentos, 67).

COSTA, R.G.; SANTOS, N.M.; SOUSA, W.H.; QUEIROGA, R.C.R.; AZEVEDO, P.S.; CARTAXO, F.Q.

Qualidade física e sensorial da carne de cordeiros de três genótipos alimentados com rações formuladas com duas relações volumoso:concentrado.

Revista Brasileira de Zootecnia, v.40, n.8, p.1781-1787, 2011. 
Rev. Bras. Saúde Prod. Anim., Salvador, v.17, n.2, p.222-236 abr./jun., 2016 http://www.rbspa.ufba.br ISSN 15199940

DANTAS, A.F.; PEREIRA FILHO, J.M.; SILVA, A.M.A.; SANTOS, E.M.; SOUSA, B.B.; CÉZAR, M.F.

Características da carcaça de ovinos Santa Inês terminados em pastejo e submetidos a diferentes níveis de suplementação. Revista Ciência e Agrotecnologia, v.32, n.4, p.12801286, 2008.

FAO. Food and Agriculture Organization of the United Nations Production. Live animals. 2012.

Disponível em:

$<$ http://faostat.fao.org/site/573/Desktop Default.aspx?PageID=573\#ancor $>$.

Acesso em: 23 set. 2014.

FERNANDES JÚNIOR, F.; RIBEIRO, E.L.A.; MIZUBUTI, I.Y.; SILVA, L.D.F.; BARBOSA, M.A.A.F.; PRADO, O.P.P.; PEREIRA, E.S.; PIMENTEL, P.G.; CONSTANTINO,

C. Características de carcaça e qualidade da carne de cordeiros Santa Inês alimentados com torta de girassol em substituição ao farelo de algodão.

Semina: Ciências Agrárias, v.34, n.6, suplemento 2, p.3999-4014, 2013.

FORTALEZA, A.P.S.; SILVA, L.D.F. da; RIBEIRO, E.L.A.; BARBERO, R. P.; MASSARO JÚNIOR, F.L.; SANTOS, A.X. dos; CASTRO, V.S.; CASTRO, F.A.B. Degradabilidade ruminal In Situ dos componentes nutritivos de alguns suplementos concentrados usados na alimentação de bovinos. Semina: Ciências Agrárias, v.30, n.2, p.481-496, 2009.

GONÇALVES, L.A.G; ZAPATA, J.F.F.; RODRIGUES, M.C.P.; BORGES, A.S. Efeitos do sexo e do tempo de maturação sobre a qualidade da carne ovina. Ciência e Tecnologia de Alimentos, v.24, n.3, p.450-467, 2004.
GRAINGER, C.; BEAUCHEMIN, K.A.

Can enteric methane emissions from ruminants be lowered without lowering their production? Animal Feed Science Technology, v.166-167, p.308-320, 2011.

HADLICH, J.C.; MORALES, D.C.; SILVEIRA, A.C.; OLIVEIRA, H.N.; CHARDULO, L.A.L. Efeito do colágeno na maciez da carne de bovinos de distintos grupos genéticos. Acta Scientiarum Animal Sciences, v.28, p.57-62, 2006.

HASHIMOTO, J.H.; ALCALDE, C.R.; SILVA, K.T.; MACEDO, F.A.F.; MEXIA, A.A.; SANTELLO, G.A.; MARTINS, E.N.; MATSUSHITA, M. Características de carcaça e da carne de caprinos Boer x Saanen confinados recebendo rações com casca do grão de soja em substituição ao milho. Revista Brasileira de Zootecnia, v.36, n.1, p.165-173, 2007.

HARVATINE, K.J.; ALLEN, M.S. Fat supplements affect fractional rates of ruminal fatty acid biohydrogenation and passage in dairy cows. Journal of Nutrition, v.136, p.677-685, 2006.

ISRAEL, H.T.; OMAR, A.R.; CONRADO, L.P.A; ALFREDO, S.B.; FRANCISCO, H.D.; GLORIA H.V. Manejo pré-abate e qualidade de carne. Revista Eletrônica de Veterinária, v.11, n.8, p.1-11, 2010.

KOZLOSKI, G. V. Bioquímica dos ruminantes. 2.ed. Santa Maria: UFSM, 2009. 216p.

LEÃO, A.G.; SILVA SOBRINHO, A.G.; MORENO, G.M.B.; SOUZA, H.B.A.; GIAMPIETRO, A.; ROSSI, R.C.; PEREZ, H.L. Características físicoquímicas e sensoriais da carne de cordeiros terminados com dietas contendo cana-de-açúcar ou silagem de milho e dois níveis de concentrado. Revista Brasileira de Zootecnia, v.41, n.5, p.1253-1262, 2012. 
Rev. Bras. Saúde Prod. Anim., Salvador, v.17, n.2, p.222-236 abr./jun., 2016 http://www.rbspa.ufba.br ISSN 15199940

MORENO, G.M.B.; SILVA

SOBRINHO, A.G.; LEÃO, A.G.;

OLIVEIRA, R.V.; UOKOO, M.J.I.;

SOUSA JÚNIO, S.C.; PEREZ, H.L.

Características morfológicas "in vivo" e da carcaça de cordeiros terminados em confinamento e suas correlações. Revista

Brasileira de Saúde e Produção Animal [online], v.11, p.888-902, 2010.

NATIONAL RESEARCH COUNCIL NRC. Nutrients requirements of small ruminants. Washington, D.C.: National Academy Press, 2007. 362p.

ORTIZ, J.S.; COSTA, C.; GARCIA, C.A.; SILVEIRA, L.V.A. Efeito de diferentes níveis de proteína bruta na ração sobre o desempenho e as características de carcaça de cordeiros terminados em CreepFeeding. Revista Brasileira de Zootecnia, v.34, n.6, p.2390-2398, 2005.

OSÓRIO, J.C.S.; OSÓRIO, M.T.M. Produção de carne ovina: Técnicas de avaliação "in vivo" e na carcaça. 2.ed. Pelotas: Universidade Federal de Pelotas, 2005, 82p.

PALMQUIST, D.L.; MATTOS, W.R.S. Metabolismo de lipídeos. In: BERCHIELLI, T.T.; PIRES, A.V.; OLIVEIRA, S.G. Nutrição de ruminantes. Jaboticabal: FUNEP, 2006. Cap.10, p.287-310.

PAULA, E.F.E.; MAIA, F. P.; CHEN, R.F.F. Óleos vegetais na nutrição de ruminantes. Revista Eletrônica Nutritime, v.9, p.2075-2103, 2012.

PEIXOTO, L.R.R.; BATISTA, A.S.M.; BOMFIM, M.A.D.; VASCONCELOS, A.M.; ARAÚJO FILHO, J.T.

Características físico-químicas e sensoriais da carne de cordeiros de diferentes genótipos terminados em confinamento. Revista Brasileira de Saúde e Produção Animal [online], v.12, n.1, p.117-125, 2011.
RAMOS, E.M.; GOMIDE L.A.M. Avaliação da qualidade de carnes: fundamentos e metodologias. Viçosa MG, UFV, 2009. 599p.

REIS, W.; JOBIM, C.C.; MACEDO, F.A.F.; MARTINS, E.N.; CECATO, U. Características da carcaça de cordeiros alimentados com dietas contendo grãos de milho conservados em diferentes formas. Revista Brasileira de Zootecnia, v.30, n.4, p.1308-1315, 2001.

RIEGEL, R.E. Bioquímica. 5.ed. São Leopoldo: Unisinos, 2012. 197p.

SANTOS, V.C. Subprodutos de oleaginosas como fontes alternativas na alimentação de cordeiros em terminação. 2011. 71f. Tese (Doutorado) - Faculdade de Ciências Agrárias, Universidade Estadual Paulista, Jaboticabal.

SAINZ, R.D. Qualidade de carcaças e da carne de ovinos e caprinos. In:

REUNIÃO ANUAL DA SOCIEDADE BRASILEIRA DE ZOOTECNIA/SIMPÓSIO INTERNACIONAL SOBRE TÓPICOS ESPECIAIS EM ZOOTECNIA, 33, 1996, Fortaleza. Anais... Fortaleza: SBZ, 1996. p.3-14.

SILVA, N.V.; SILVA, J.H.V.; COELHO, M.S.; OLIVEIRA, E.R.A.; ARAÚJO, J.A.; AMÂNCIO, A.L.L. Características de Carcaça e Carne Ovina: Uma Abordagem dasVariáveis Metodológicas e Fatores de Influencia. Acta Veterinaria Brasilica, v.2, n.4, p.103-110, 2008

SILVA SOBRINHO, A.G. da; PURCHAS, R.W.; KADIM, I.T.; YAMAMOTO, S.M. Características de qualidade da carne de ovinos de diferentes genótipos e idades ao abate.

Revista Brasileira de Zootecnia, v.34, n.3, p.1070-1078, 2005. 
Rev. Bras. Saúde Prod. Anim., Salvador, v.17, n.2, p.222-236 abr./jun., 2016 http://www.rbspa.ufba.br

TELLES, M.M. Caracterização dos grãos, torta e óleo de três variedades de girassol (Helianthus annuus L.) e estabilidade do óleo bruto. 2006. 70f. Dissertação (Mestrado em Ciência dos Alimentos) - Departamento de Ciência e Tecnologia de Alimentos do Centro de Ciências Agrárias, Universidade Federal de Santa Catarina, Florianópolis.

VAN SOEST, P.J.; ROBERTSON, J.B.; LEWIS, B.A. Methods for dietary fiber, neutral detergent fiber, and nonstarch polysaccharides in relation to animal nutrition. Journal of Dairy Science, v.74, p.3583-3597, 1991.

ZAPATA, J.F.F.; SEABRA, L.M.J.; NOGUEIRA, C.M.; BARROS, N.

Estudo da qualidade da carne ovina do nordeste brasileiro: propriedades físicas e sensoriais. Ciência e Tecnologia de Alimentos, v.20, n.2, p.274-277, 2000.

ZEOLA, N.M.B.L.; SOUZA, P.A.; SOUZA, H.B.A.; SILVA SOBRINHO, A.G. Parâmetros qualitativos da carne ovina: um enfoque à maturação $\mathrm{e}$ marinação. Revista Portuguesa de Ciência Veterinária, v.102, n.563, p.215-224, 2007.

Data de recebimento: 27/04/2015

Data de aprovação: 01/06/2016 